\title{
INCÊNDIOS NA AMAZÔNIA BRASILEIRA: ESTIMATIVA DA EMISSÃO DE GASES DO EFEITO ESTUFA PELA QUEIMA DE DIFERENTES ECOSSISTEMAS DE RORAIMA NA PASSAGEM DO EVENTO "EL NIÑO" (1997/98)
}

\author{
Reinaldo Imbrozio BARBOSA', Philip Martin FEARNSIDE ${ }^{2}$
}

RESUMO - Foi estimada a área queimada, a biomassa vegetal total acima e abaixo do solo, a formação de carvão, a eficiência de queimada e a concentração de carbono de diferentes paisagens naturais e agroecossistemas que foram atingidos pelos incêndios ocorridos durante a passagem do "El Niño" em 1997/98 no Estado de Roraima, extremo norte da Amazônia Brasileira. O objetivo foi o de calcular a emissão bruta de gases do efeito estufa liberados por combustão das diversas classes de biomassa que compõem cada tipo fitofisionômico atingido. A área total efetivamente queimada foi estimada entre 38.144-40.678 $\mathrm{km}^{2}$, sendo 11.394-13.928 $\mathrm{km}^{2}$ de florestas primárias (intactas, em pé) e, o restante, de savanas (22.583 $\left.\mathrm{km}^{2}\right)$, campinas / campinaranas $\left(1.388 \mathrm{~km}^{2}\right)$ e ambientes florestais já transformados como pastagens, área agricolas e florestas secundárias $\left(2.780 \mathrm{~km}^{2}\right)$, $\mathrm{O}$ total de carbono afetado pelos incêndios foi de 42,558 milhões de toneladas, sendo que 19,73 milhões foram liberados por combustão, 22,33 milhões seguiram para a classe de decomposição e 0,52 milhões foram depositados nos sistemas na forma de carvão (estoque de longo prazo). A emissão bruta de gases do efeito estufa, em milhões de toneladas do gás, considerando apenas o emitido por combustão foi de 17,3 de $\mathrm{CO}_{2}, 0,21-0,35 \mathrm{de} \mathrm{CH}_{4}, 1,99-3,68 \mathrm{de} \mathrm{CO}, 0,001-0,003$ de $\mathrm{N}_{2} \mathrm{O}, 0,06-0,09$ de $\mathrm{NO}_{\mathrm{x}}$ e 0,25 de hidrocarbonetos não-metânicos (HCNM). $\mathrm{O}$ total de carbono equivalente a $\mathrm{CO}_{2}$ emitido por combustão, quando considerado o potencial de aquecimento global de cada gás em um horizonte de tempo de 100 anos utilizado pelo IPCC, foi de 6,1-7,0 milhões de toneladas.

Palavras-chave: incêndios florestais, carbono, Amazônia, Roraima, efeito estufa, El Niño, aquecimento global.

Fires in the Brazilian Amazon: Estimate of Greenhouse Gas Emissions from Burning of Ecosystems in Roraima, During the 1997-98 "EI Niño" Event

ABSTRACT - The area burned, total biomass above and below-ground, charcoal formation, burning efficiency and the carbon concentration were estimated for the different natural landscapes and agricultural systems that were exposed to fire during the "El Niño" of 1997-98 in the state of Roraima, in the northernmost part of Brazilian Amazonia. The objective was to calculate the gross emissions of greenhouse gases released by combustion from the various biomass classes comprising each landscape type. The total area bumed was $38,144-40,678 \mathrm{~km}^{2}$, of which $11,394-13,928 \mathrm{~km}^{2}$ was intact primary forest, $22,583 \mathrm{~km}^{2}$ was savanna, $1,388 \mathrm{~km}^{2}$ was white sand scrub formations, and $2,780 \mathrm{~km}^{2}$ was pastures, secondary forest and agricultural plots. Total carbon affected by the fire was $42.58 \times 10^{6}$ tons $(\mathrm{t})$, with $19.73 \times 10^{6} \mathrm{t}$ being released from combustion, $22.33 \times 10^{6} \mathrm{t}$ from decomposition, and $0.552 \times 10^{6} \mathrm{t}$ converted to charcoal (longterm carbon storage) formed during the burns. Gross emissions of greenhouse gases emitted by combustion were $17.3 \times 10^{6} \mathrm{t} \mathrm{CO}_{2}, 0.21-0.35 \times 10^{6} \mathrm{t} \mathrm{CH}_{4}, 1.99-3.68 \times 10^{6} \mathrm{tCO}, 0.001-0.003 \times 10^{6} \mathrm{t} \mathrm{N}_{2} \mathrm{O}, 0.06-$ $0.09 \times 10^{6} \mathrm{t} \mathrm{NO}_{\mathrm{x}}$ and $0.25 \times 10^{6} \mathrm{t} \mathrm{NMHC}$ (non-methane hydrocarbons). The total emission in carbon equivalent to $\mathrm{CO}_{2}$ emitted by combustion, based on the global warming potentials for each gas over the 100-yr horizon used by the IPCC, was 6.1-7.0 × $10^{6} \mathrm{t} \mathrm{C}$.

Key- words: forest fires, carbon, Amazônia, Roraima, greenhouse effect, El Niño, global warming.

\footnotetext{
'. INPA/CTA-Conv. INPA/GERR - Caixa Postal 96 - 69301-970 Boa Vista/Roraima-Brasil. e-mail: imbrozio@technet.com.br

2. INPA/Coordenação de Pesquisas em Ecologia - Caixa Postal 478 - 69011-970 Manaus/ Amazonas-Brasil.e-mail: pmfearn@inpa.gov.br
} 


\section{INTRODUÇÃO}

Incêndios florestais de grandes proporções em regiões com elevada umidade na Amazônia poderiam ser considerados como eventos raros, sendo que poucas pessoas teriam dado crédito a esta idéia há pouco tempo atrás (Uhl et al., 1988; Kauffman, 1991; Nelson \& Irmão, 1998). Entretanto, entre o final de 1997 e o início de 1998, ocorreram incêndios que penetraram não só em florestas primárias como também em outros diferentes tipos de ecossistemas do Estado de Roraima, situado no extremo norte da Amazônia Brasileira (Barbosa, 1998a;b;c; IBAMA, 1998; INPE, 1998; 1999a; Shulze, 1998). Fogos em eco-regiões como savanas e sistemas florestais transformados (capoeiras, pastagens e desmatamentos), que tradicionalmente queimam neste período, se alastraram por milhares de quilômetros quadrados e atingiram uma grande área de floresta primária (intacta, em pé), provocando a morte de árvores e a emissão de milhões de toneladas de gases do efeito estufa para a atmosfera. A enorme proporção do fogo foi creditada, principalmente, à estiagem provocada pelo forte fềnomeno "El Niño" do biênio 1997/98. Entretanto, o grande fogo ocorrido em Roraima não deve ser visto como um evento ocasionado exclusivamente por este efeito climático. Mais do que isto, ele deve ser visto como uma série de fatores que agiram simultaneamente onde, o "El Niño", foi um maximizador de agentes pré-existentes que ocasionaram a queima de grandes áreas de florestas em Roraima. Na verdade, a probabilidade deste risco ocorrer ao longo do tempo pode ser esperada a aumentar devido a pressão de assentamentos humanos em áreas de floresta por toda a Amazônia, amplificados pelo incremento nas atividades de exploração florestal, agricultura de corte e queima e conversão de florestas primárias em pastagens, todos incrementando a vulnerabilidade das florestas adjacentes (Kauffman et al., 1988; Negreiros et al., 1996; Cochrane, 1999; Nepstad et al., 1999a;b).

Devido ao recente interesse e as poucas oportunidades de observações em grandes áreas contínuas, são raros os estudos que tentam avaliar os riscos de susceptibilidade de incêndios na Amazônia provocados por algum tipo de desequilibrio climático e/ou antrópico. Pelo mesmo motivo, não existem investigações que se reportem a liberação de gases do efeito estufa provocados por incêndios desta natureza. Com o crescimento das atividades humanas na Amazônia, há necessidade de se aumentar o volume de informações sobre os impactos climáticos futuros que este tipo de evento pode acarretar ao nível regional e global. Pensando nisto, nós objetivamos calcular a emissão de gases do efeito estufa, provocada pelos incêndios de Roraima em diferentes tipos de sistemas naturais e agroecossistemas que sofreram a ação do fogo entre 1997 e 1998. Para fazer os cálculos nós estimamos os 
seguintes parâmetros: (a) a área de cada sistema natural e agroecossistema atingido, (b) a biomassa vegetal total (acima e abaixo do solo) por unidade de área, (c) a mortalidade arbórea devido ao fogo, (d) a formação de carvão nos sistemas atingidos, (e) a eficiência de queimada para as diferentes classes vegetais que compõe cada sistema e (f) a concentração de carbono em cada uma destas classes.

\section{Descrição Geral de Área}

Roraima é um dos antigos territórios federais transformados em estado da federação pela Constituição Federal de 1988, situado no extremo norte da Amazônia brasileira. Entre 1980 e 1998 , a população local triplicou, passando de 82.018 para 260.705 habitantes (IBGE, 1999). A explosão migratória deste periodo foi incentivada pelo próprio poder público local em três grandes fases: (a) ao final da década de 1970, com apoio do Governo Federal, dentro do Programa de Pólos da Amazônia (POLOAMAZÔNIA), sub-programa POLORORAIMA, (b) ao final da década de 1980, quando da transformação do território em estado, através do "boom" mineral em terras indígenas Yanomami e (c) ao início dos anos 1990 dentro dos programas estaduais de recrutamento de migrantes em outras regiões do país com problemas fundiários (Barbosa, 1993). O crescimento populacional provocou um aumento de 55,6 vezes na área total de florestas desmatadas, passando de $100 \mathrm{~km}^{2}$ em 1978 para $5.560 \mathrm{~km}^{2}$ em 1997 (INPE, 1999b).

A vegetação natural de Roraima é um mosaico de paisagens que vão de savanas (nordeste) a florestas (sul e oeste), passando por diferentes tipos de sistemas oligotróficos como campinas e campinaranas no centrosul do Estado (Silva, 1997). A precipitação pluviométrica anual é variável e pode se estabelecer em um gradiente que vai de $1.000 \mathrm{~mm}$ (extremo nordeste das savanas) até $2.300 \mathrm{~mm}$ (regiões sul e extremo oeste) (Barbosa, 1997). A localidade com maior volume de dados climáticos é a da capital Boa Vista. Sua média anual de precipitação é de $1.614 \mathrm{~mm}$ (1910 a 1995). Entre setembro de 1997 e março de 1998 , a precipitação foi de apenas $30,6 \mathrm{~mm}$ nesta região, quando o esperado pela média histórica do mesmo período seria de $352 \mathrm{~mm}$ (DEFARA/INMET, 1999). A umidade relativa do ar (\%) ficou abaixo dos $60 \%$ entre fevereiro e março de 1998 (MAA/INMET, 1998).

\section{Área dos Sistemas Naturais e Agroecossistemas Atingidos}

\section{Área Original}

Para determinar a área total atingida pelo fogo, dimensionamos a área original de todas as fitofisionomias originais existentes em Roraima. Utilizamos como base uma digitalização do Mapa de Vegetação da Amazônia na escala de 1:2.500.000 (SUDAM/IBGE, 1989), porque esta base usa a classificação tipológica padrão da vegetação brasileira descrita 
em IBGE (1992). Após a determinação inacroespacial dos tipos que fazem parte do cenário regional, todo o conjunto foi escaneado e codificado por cores para facilitar a medida de área original. Baseado em observações de campo e no Mosaico de Imagens de Satélite L.ANDSAT TM (1:1.000.000) (SENAGRO/ITERAIMA, 1996), realizamos ajustes e modificaçòes no mapa digitalizado, devido a algumas incorreções existentes, como por exemplo campinas denominadas como savanas ou florestas densas definidas como contatos. Com auxilio do IDRISI (Eastman, 1995), um programa de computador que analisa dados de informação geográfica para classificação espacial (no caso, tons de cores), estimamos o número de "pixels" de cada tipo de vegetação e, proporcionalizamos a área de cada feição vegetal, considerando a área total de Roraima como $225.116,1 \mathrm{~km}^{2}$.

Para estimar a área liquida presente em $1997 / 98$ por tipologia original, foi necessário fazer dois tipos de descontos nas áreas calculadas: (a) das áreas antropizadas (rurais e urbanas) e (b) dos cursos d'água (principais rios). As áreas rurais foram quantificadas em função dos resultados alcançados pelo INPE (1999b) para áreas desmatadas até 1997 e, atualizadas até 1998 pela média da área anual de desmatamentos ocorridos entre 1992/97. A distribuição das áreas desmatadas em pastagens, agricultura e capoeiras (florestas secundárias) até 1997/98, foi proporcionalizada em função de uma composição média de quatro resultados: (a) censo agropecuário de 1985 (IBGE, 1985), (b) censo agropecuário de 1995/96 (IBGE, 1995-96), (c) Fearnside (1996) para as três paisagens equilibradas no ano de 1990 e (d) o resumo dos diagnósticos dos assentamentos do INCRA em Roraima de 1998/99 (Luz, 1999). As áreas determinadas para as três categorias antropizadas foram subtraídas de cada eco-região-florestal a que pertenciam, proporcionalmente ao número de quilômetros lineares de estradas/vicinais existentes em cada sistema, assumindo uma relação direta entre estradas e áreas desmatadas. As áreas antropizadas urbanas foram computadas através da extrapolação do número de "pixels" médios contidos em cada sede municipal. Do mesmo modo que as rurais, foram descontadas de cada tipo paisagístico onde a cidade se encontra. Para estimar a área dos principais cursos d'água, utilizamos o mesmo procedimento para o cálculo das unidades tipológicas.

\section{Área Queimada}

Para o cálculo da área atingida pelo fogo por tipologia florestal e oligotrófica, digitalizamos as coordenadas geográficas obtidas em 16,5 horas de sobrevôos por Barbosa (1998b) no Sistema de Informação Geográfica (SGI/INPE, versão 7.0) utilizado pela Secretaria Executiva do Zoneamento Ecológico-Econômico de Roraima (ZEE/RR). Estes pontos geográficos sofreram adições e 
correções em seus limites originais em função dos ajustes de campo e dos relatórios parciais apresentados pelo INPE (1998; 1999a) quando da análise de imagens dos satélites LANDSAT TM e DMSP. Feito isto, se estabeleceram três blocos de queima distribuidos ao longo da orla florestal que envolve a regiäo de savanas de Roraima. Estes blocos de queima representavam as grandes divisões regionais onde o fogo estava presente: (a) Bloco 1: setor leste, entre a margem esquerda dos rios Branco e Tacutu (Cantá - RR 170 - Rio Anauá), (b) Bloco 2: setor oeste; entre a margem direita dos rios Branco e Uraricoera (Caracaraí - Rio Uraricoera) e (c) Bloco 3: setor norte; entre a margem esquerda do rio Uraricoera e a direita do rio Tacutu (Ilha de Maracá - Pacaraima). Além disto, eles foram subdivididos em zonas de intensidade de queima florestal para indicar as diferenças existentes em cada uma destas subdivisões e, o tratamento diferenciado que cada uma delas deveria sofrer: (a) alta intensidade: mais de $50 \%$ das áreas florestadas atingidas, (b) média intensidade: entre 5 e $50 \%$ e (c) baixa intensidade: abaixo de $5 \%$, mas com algumas alternâncias.

Os blocos de queima foram dispostos sobre a base fitofisionômica montada a partir do mapa da SUDAM/ IBGE (1989) para estimar a área atingida pelo fogo por cada tipo florestal e oligotrófico (campinas e campinaranas). A área atingida representava a área total onde o fogo estava presente (Fig 1). Enurelanto. para os sistemas florestais, for necessario realizar descontos (antropismos, cursos d'água, outras paisagens não-queinadas. cki) para evitar sobreposiçòes e/ou contabilização de ambientes que não queimaram. Além disto, a área de flurestas (já descontada) tambem teve que sofrer um ajuste em função da intensidade de queima onde ela se encontrava. Isto foi devido ao comportamento diferenciado do fogo em cada uma das zonas de intensidade. Para isto, nós definimos um fator de queima para cada uma das áreas em função de fotografias aéreas obtidas nos sobrevôos realizados durante e após os incêndios. Emborà com baixa qualidade e representando uma pequena extensão, este foi o meio encontrado para não provocar maiores distorções do que aquelas já naturalmente existentes em um estudo desta magnitude. Por esta metodologia. a área efetivamente queimada do florestas (área onde o fogo realmente provocou algum tipo de dano no sistema) foi de $11.394 \mathrm{~km}^{2}$ (Tab. 1).

Pelo alto grau de incertezas devido ao fogo superficial que não provocou estresse nas copas das árvores de algumas localidades e, portanto, não foi detectado pelas fotografias aéreas e nem pelas imagens de satélite, nós adotamos um intervalo de área queimada para efeito do cálculo das emissões de gases. Este intervalo foi formado pelo valor acima calculado e, pelo uso do fator de queima observado pela equipe de 


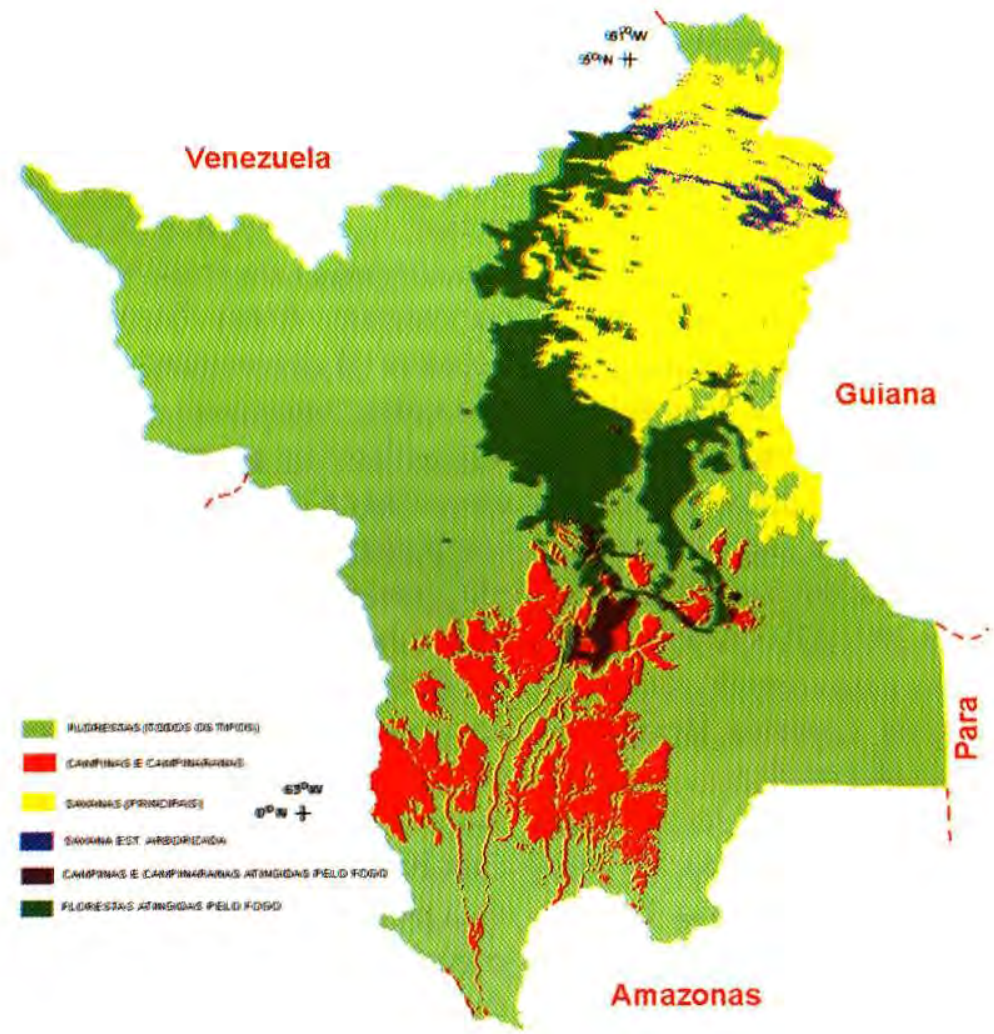

Figura 1. Área bruta dos sistemas florestais e oligotróficos (campinas/campinaranas) atingidas pelos incêndios.

Tabela 1. Área $\left(\mathrm{km}^{2}\right)$ de floresta intacta atingida e efetivamente queimada, por zona de impacto do fogo (somatório de todos os blocos de queima).

\begin{tabular}{|c|c|c|c|c|c|c|c|c|c|}
\hline \multirow[b]{2}{*}{$\begin{array}{l}\text { Zona de impacto do } \\
\text { fogo }\end{array}$} & \multirow[b]{2}{*}{$\begin{array}{c}\text { Área } \\
\text { Atingida } \\
\text { Bruta } \\
\text { (kmr) }\end{array}$} & \multicolumn{3}{|c|}{ Descontos } & \multirow[b]{2}{*}{$\begin{array}{l}\text { Área } \\
\text { Atingida } \\
\text { Liquida } \\
\left(\mathrm{km}^{\prime}\right)\end{array}$} & \multirow[b]{2}{*}{$\begin{array}{c}\text { Fator de } \\
\text { Queima } \\
\text { Medio (1) } \\
(\%)\end{array}$} & \multirow[b]{2}{*}{$\begin{array}{c}\text { Area } \\
\text { Efetivamente } \\
\text { Queimada } \\
\left(\mathrm{km}^{2}\right)\end{array}$} & \multirow[b]{2}{*}{$\begin{array}{c}\text { Fator de } \\
\text { Queirna } \\
\text { Madio (2) } \\
(\%)\end{array}$} & \multirow[b]{2}{*}{$\begin{array}{c}\text { Area } \\
\text { Efetivamente } \\
\text { Queimada } \\
\left(\mathrm{km}^{2}\right)\end{array}$} \\
\hline & & $\begin{array}{l}\text { Rios } \\
\left(\mathrm{km}^{2}\right)\end{array}$ & $\begin{array}{c}\text { Outros } \\
\text { Ambientes } \\
\text { Naturais } \\
\left(\mathrm{km}^{2}\right)\end{array}$ & $\begin{array}{l}\text { Antropismos } \\
\qquad\left(\mathrm{km}^{2}\right)\end{array}$ & & & & & \\
\hline Alto Impacto & 13687 & 120 & 981 & 1789 & 10797 & 85,1 & 9189 & - & - \\
\hline Médio Impacto & 6022 & 48 & 416 & 1145 & 4413 & 33,7 & 1487 & $=$ & - \\
\hline Baixo Impacto & 1583 & 12 & 23 & 320 & 1229 & 7,3 & 90 & - & - \\
\hline Sub-total & 21292 & 180 & 1419 & 3253 & 16439 & 52,7 & 10766 & 80,9 & 13299 \\
\hline Alto impacto (SN) (3) & 2049 & 17 & 0 & 20 & 2012 & 31,2 & 628 & - & 628 \\
\hline Total & 23341 & 198 & 1419 & 3273 & 18451 & - & 11394 & - & 13928 \\
\hline
\end{tabular}

(1) Cálculo considerando os fatores de queima determinados para cada bloco de queima e por zona de impacto do fogo.

(2) Cáculo considerando o fator determinado pelo IBAMA (1998), para a área total do incèndio em sistemas florestais.

(3) SN - Area de tensão ecológica: contato savana/floresta sazonal. Foi determinada juntamente com os transectos realizados nas savanas porque eles cortavam este tipo de paisagem. Este calculo foi feito em separado. 
trabalho terrestre do IBAMA (1998), que registrou a porcentagem de $80,9 \%$ de área florestal com algum tipo de dano (efetivamente queimada) pelo fogo, independente da intensidade do incêndio. Logo, aplicando esta porcentagem sobre o total de área atingida, determinamos que o intervalo para área efetivamente queimada se estabeleceria entre 11.394-13.928 $\mathrm{km}^{2}$ ou, entre $7,4 \%$ e $9,0 \%$ de toda a área florestada presente. A título de cálculo das emissões, usaremos o valor médio deste intervalo.

Nossa estimativa atual esta acima dos primeiros resultados alcançados por Barbosa (1998a;b) em sobrevôos nas regiões atingidas (7.800-9.200 km²) e, pelo INPE (1999) a partir de imagens de satélite LANDSAT / TM $\left(11.730 \mathrm{~km}^{2}\right)$. No primeiro caso, várias áreas deixaram de ser quantificadas devido à limitação da cobertura aérea e, no segundo, o limite se deu devido a qualidade das imagens e a impossibilidade de detecção de fogos superficiais, sem estressamento da cobertura foliar das árvores. Entretanto, em qualquer das estimativas citadas, os valores são sempre superiores a área total já desmatada em Roraima até 1997 $\left(5.560 \mathrm{~km}^{2}\right)$ e muito acima das estimativas anunciadas anteriormente pelo governo para o evento $(3.000$ $\mathrm{km}^{2}$ ) (Braga, 1998).

Quanto ao procedimento para determinar a proporção de área queimada de ambientes antrópicos florestais (pastagens, capoeiras e cultivos agrícolas), realizamos quatro (4) transectos terrestres distribuidos nas zonas de impacto do fogo (descritas acima): (a) transecto 1 (médio impacto): $147 \mathrm{~km}$ lineares entre a região do Cantá e a Vila União (RR 170), (b) transecto 2 (baixo impacto): $76 \mathrm{~km}$ lineares entre as Vilas Novo Paraiso (BR 174/210), Martins Pereira, Moderna e fechando novamente com Novo Paraíso, (c) transecto 3 (médio impacto): $60 \mathrm{~km}$ lineares entre Mucajai e a divisa intermunicipal de Iracema e Caracarai e (d) transecto 4 (alto impacto): $64 \mathrm{~km}$ lineares entre a vicinal 1 do Apiaú, vicinal 9, travessão da 9, Ribeiro Campos e vicinal 7. Em cada um destes transectos nós quantificamos o número de lotes antropizados por categoria e por sua condição: "queimado" ou "não-queimado". Feito isto, estimamos a porcentagem média de área queimada por zona de impacto de fogo nestes ambientes florestais transformados. Dos $5.776 \mathrm{~km}^{2}$ de áreas antrópicas presentes em Roraima até 1998 (já incluido $220 \mathrm{~km}^{2}$ de novos desmatamentos), calculamos que $48,1 \%\left(2.780 \mathrm{~km}^{2}\right)$ haviam sido efetivamente queimadas. Os maiores fatores de queima foram determinados para as regiões localizadas nas zonas de alta intensidade de fogo, para capoeiras $(73,7 \%)$ e pastagens $(62,7 \%)$. O menor fator foi encontrado para áreas de cultivo agricola nas regiões de baixa intensidade $(15,4 \%)$.

Para os sistemas oligotróficos, as estimativas alcançaram um total de $1.388 \mathrm{~km}^{2}$ de área queimada, levando 
em consideração os procedimentos adotados anteriormente. Para o cálculo da área total queimada nas savanas, o procedimento foi descrito em Barbosa (1998b) e, leva em consideração as medidas realizadas entre julho de 1997 e junho de 1998 nos transectos estabelecidos ao longo de $540,1 \mathrm{~km}$ lineares de estradas que cortam todas as principais fisionomias de savanas de Roraima. A área queimada desta paisagem totalizou $22.583 \mathrm{~km}^{2}$. Um resumo das áreas originais e das efetivamente queimadas por tipologia vegetal é dado na Tabela 2.

\section{Biomassa Vegetal Total Original}

\section{Biomassa Presente}

O procedimento de cálculo para a maioria das eco-regiões florestais (densas e não-densas), foi baseado no método de expansão de volume $\left(\mathrm{m}^{3} /\right.$ ha) em biomassa ( $t / h a)$ de Brown \& Lugo (1992), ajustado pelo método de Fearnside (1992). Para Roraima, este método sofreu ajustes nas categorias "biomassa morta acima do solo" e "biomassa abaixo do solo". Para estes dois itens, foram adicionados novos estudos aos anteriormente adotados por Fearnside (1992), como por exemplo os da Ilha de Maracá (Scott et al., 1992; Thompson et al., 1992; Nascimento, 1994, Villela, 1995) e, descartados outros que não se enquadravam nas caracteristicas de fisionomia vegetal existentes em Roraima. Os dados volumétricos $\left(\mathrm{m}^{3}\right)$ ha) em escala regional foram obtidos dos volumes $8,9,10,11,14$ e 18 do RADAMBRASIL (1975-1978), que abrange toda a região (e vizinhanças) onde está localizado o Estado de Roraima. Portanto, possuindo tipos fisonômicos semelhantes. A biomassa média total (ponderada) para todas as florestas densas foi de $320 \mathrm{t} / \mathrm{ha}$ e, para as florestas não-densas foi de $279 \mathrm{t} / \mathrm{ha}$ (Tab. 3). Em ambos os casos, há uma redução de $25 \%$ e $34 \%$, respectivamente, em relação aos valores apresentados por Fearnside (1997b) para estimativas das emissões de carbono por desmatamento em Roraima no ano de 1990.

Para os sistemas não-florestais oligotróficos (campinas e campinaranas), além dos dados de volumetria do RADAMBRASIL, também fizemos uso dos estudos existentes em eco-regiões similares na Venezuela (Bongers et al., 1985; Klinge \& Herrera, 1983) e de um trabalho realizado no sul de Roraima por uma equipe da Coordenação de Pesquisas em Silvicultura Tropical do INPA em 1992 (Niro Higuchi, comunicação pessoal). Os valores de biomassa total variaram de $52 \mathrm{t} / \mathrm{ha}$ a $117 \mathrm{t} / \mathrm{ha}$ para estes sistemas. As demais eco-regiões não-florestais (savanas), foram ajustadas através dos estudos de R.I.B. que estão sendo realizados desde 1994 para determinação da emissão de gases do efeito estufa pela queima de savanas na Amazônia. Para a obtenção da biomassa abaixo do solo em sistemas de savanas, utilizamos as proporções obtidas por Castro \& Kauffman (1998) em cerrados do Brasil Central. No geral, a biomassa total (acima e abaixo 
Tabela 2. Área original e área efetivamente queimada dos tipos fitofisionômicos (naturais e agroecossistemas) presentes em Roraima entre 1997/98.

\begin{tabular}{|c|c|c|c|c|c|c|c|}
\hline \multirow[b]{2}{*}{ Categoria } & \multirow[b]{2}{*}{ Codigo } & \multirow[b]{2}{*}{ Grpo } & \multirow[b]{2}{*}{ Sib-gnpo } & \multirow[b]{2}{*}{ Classe } & \multicolumn{2}{|c|}{ Área 1997/98 } & \multirow{2}{*}{$\begin{array}{l}(\%) \text { da área } \\
\text { queimada em } \\
\text { relaçăo á área } \\
\text { presente }\end{array}$} \\
\hline & & & & & Presente & $\begin{array}{l}\text { Eletivamente } \\
\text { Queimada }\end{array}$ & \\
\hline \multirow[t]{5}{*}{ Foresta Densa } & $\mathrm{Da}-0$ & floresta ambrofila & ficresta densa & aluial & 2573 & 0 & 0,0 \\
\hline & $D b-0$ & filoresta ortbrobila & floresta densa & terras baixas & 7959 & 0 & 0.0 \\
\hline & Dmo & Aloresta ombrófila & floresta densa & montana & 21457 & 0 & 0,0 \\
\hline & Ds-0 & floresta ormbrofila & floresta dersa & scbmorkana & 72821 & 2657 & 3,6 \\
\hline & \multicolumn{2}{|c|}{ Sub-total Floresta Densa } & & & 104810 & 2657 & 2.5 \\
\hline \multirow{7}{*}{ Floresta Năo-Densa } & As. 0 & floresta ontrófila & foresta aberta & subriortana & 8197 & 4 & 0,0 \\
\hline & Fs-0 & foresta sazonal & semdecidua & subrnortana & 1286 & 485 & 37,7 \\
\hline & ONO & $\begin{array}{l}\text { áreas de tensáo ecológica e } \\
\text { contalo }\end{array}$ & & $\begin{array}{l}\text { lloresta onbrófila/ floresta } \\
\text { sazonal }\end{array}$ & 17230 & 7010 & 40,7 \\
\hline & SNOO & $\begin{array}{l}\text { áreas de tensăo ecológica e } \\
\text { contalo }\end{array}$ & & savana/fioresta sazonal & 1975 & 628 & 31,8 \\
\hline & SOO & $\begin{array}{l}\text { áreas de tensáo ecologica e } \\
\text { contato }\end{array}$ & & savana/loresta orrbrolila & 4456 & 215 & 4,8 \\
\hline & LOO & $\begin{array}{l}\text { áreas de tensáo ecolbogica e } \\
\text { cortalo }\end{array}$ & & $\begin{array}{l}\text { vegetaçăo oligotrófica } \\
\text { lertosa de brejos e } \\
\text { areais/Horesta ombrofila }\end{array}$ & 16674 & 394 & 2.4 \\
\hline & \multicolumn{2}{|c|}{ SLb-lotal Floresta Nâ-Densa } & & & 49817 & 8737 & 17.5 \\
\hline \multirow{10}{*}{ Năo-forestal } & Ld-0 & $\begin{array}{l}\text { vegetaçăo oligotrofica } \\
\text { lenhosa de brejos } \theta \text { areais }\end{array}$ & & arbórea densa & 12256 & 524 & 4,3 \\
\hline & La-0 & $\begin{array}{l}\text { vegetaçấo oligotrofica } \\
\text { lentosa de brejos e areais }\end{array}$ & & arbórea aberta & 134 & 0 & 0.0 \\
\hline & $\operatorname{Lg}-0$ & $\begin{array}{l}\text { vegetaçáa oligotrofica } \\
\text { lentosa de brejos e areais }\end{array}$ & & gramineoterhosa & 11573 & 864 & 7,5 \\
\hline & \multicolumn{2}{|c|}{ Sub-total Oligotróficas } & & & 23962 & 1388 & 5,8 \\
\hline & $m n-0$ & refúgio ecológico & alta altitude & montana & 205 & 32 & 15.5 \\
\hline & $\mathrm{Sg} \cdot 0$ & savana & cenrado & gramineo-lerhosa & 15004 & 7932 & 52,9 \\
\hline & $\mathrm{Sp}-0(2)$ & savana & cenrado & parque & 12443 & 7329 & 58,9 \\
\hline & $\operatorname{Td}-3(2)$ & savara estépica & Campos de Poraima & arbórea dersa & 2313 & 1779 & 76,9 \\
\hline & $T p-3$ & savara estepica & Carpos de Roraima & parque & 8733 & 5511 & 63.1 \\
\hline & \multicolumn{2}{|c|}{ Sub-total savana } & & & 38697 & 22563 & 58,4 \\
\hline - & Rural & pastagers & & & 3063 & 1538 & 50,2 \\
\hline \multirow{6}{*}{ Antróopico (1) } & & capoeiras & & & 1699 & 854 & 50,3 \\
\hline & & & & & & & \\
\hline & & cultivos agrivodas & & & 794 & 169 & 21,2 \\
\hline & & desmatamentos $/ 1998$ & & & 220 & 220 & 100.0 \\
\hline & \multicolumn{2}{|c|}{ Sub-total Antrópicos } & & & 5776 & 2780 & 48.1 \\
\hline & Urbano & cidades & & & 251 & 0 & - \\
\hline Cursos đóaua (3) & & & & & 1803 & 0 & - \\
\hline Área lotal $\left(\mathrm{km}^{\prime}\right)$ & & & & & 225116 & 38144 & 16,9 \\
\hline
\end{tabular}

(1) Rural: considerado como troca do uso da terra apenas em áreas de floresta principalmente das tipologias Ds, ON. Fs. LO e As; Urbano: sedes municipais (distribuidas da seguinte forma: 5 para Ds: 4 para ON; 1 para LO: 1 para SN; 2 para Sg: 1 para Sp; e 1 para Tp). Desmatamento foi considerado como totalmente atingido pelo togo.

(2) Sp representa, a título de cálculo, a soma de Sp com Sa e. Td representa, a título de cálculo, a soma de Td com Ta

(3) Representa os principais rios de Roraima. 
Tabela 3. Biomassa total estimada por tipologia vegetal ( $t / \mathrm{ha}$ ) em Roraima.

\begin{tabular}{|c|c|c|c|c|c|}
\hline \multirow{3}{*}{ C a tegaria } & \multirow{3}{*}{ Codigo } & \multicolumn{4}{|c|}{ Biomassa (1/ha) (2) } \\
\hline & & \multicolumn{2}{|c|}{ A cim a do 5010} & \multirow{2}{*}{ A balxo Viva } & \multirow{2}{*}{ Total } \\
\hline & & Viva & Morta & & \\
\hline \multirow{5}{*}{ Floresta Densa } & $D$ a -0 & 275 & 21 & 47 & 343 \\
\hline & $D b-0$ & 276 & 21 & 47 & 345 \\
\hline & $0 \mathrm{~m}=0$ & 232 & 18 & 40 & 290 \\
\hline & $D s-0$ & 261 & 20 & 45 & 326 \\
\hline & Modla Pond. Floresis oonas & 2.57 & 20 & 44 & 320 \\
\hline \multirow{7}{*}{ Floresla $N$ a o. D ensa } & A s -0 & 226 & 17 & 39 & 283 \\
\hline & $F s=0$ & 226 & 17 & 39 & 283 \\
\hline & $O N \cdot O$ & 226 & 17 & 39 & 283 \\
\hline & $S N-O$ & 158 & 12 & 27 & 197 \\
\hline & 50.0 & 158 & 12 & 27 & 197 \\
\hline & LO $=0$ & 234 & 32 & 40 & 306 \\
\hline & Med la Pond, Floresta NaO-Dena a & 220 & 22 & 38 & 279 \\
\hline \multirow[t]{10}{*}{ Năo-llärestal } & $L d-0$ & 39.8 & 7.8 & 69.0 & 117 \\
\hline & $L a \cdot 0$ & 33,8 & 5.0 & 21,3 & 60 \\
\hline & $\operatorname{Lg}-0$ & 5.8 & 3,7 & 42.0 & 52 \\
\hline & Medla Pond. Ollgolrólicas & 23,3 & 5,8 & 55,7 & 85 \\
\hline & $\mathrm{rm}-0$ & 2.7 & 0.4 & 10,0 & 13 \\
\hline & $S_{g}-0$ & 2,9 & 0,4 & 10,9 & 14 \\
\hline & $S p \cdot 0$ & 5,4 & 0,6 & 20,3 & 26 \\
\hline & $T d \cdot 3$ & 26.1 & 2,9 & 66,5 & 95 \\
\hline & $T p-3$ & 5,2 & 0.4 & 13.3 & 19 \\
\hline & Médla Pond, savanae & 5,6 & 0,6 & 17,8 & 24 \\
\hline \multirow[t]{6}{*}{ Antropico (1) } & Aural & & & & \\
\hline & pastagans (1) & 11.2 & 65,5 & 12,2 & 89 \\
\hline & capoelras & 30,9 & 112.4 & 22.8 & 166 \\
\hline & cultivos ag ticolas & 0.4 & 59,3 & 9,5 & 69 \\
\hline & desmatamentos/1998 & 0.0 & 271,2 & 43,2 & 314 \\
\hline & Modia Pond. Antrópleos & 15,1 & 86,3 & 16,1 & 117 \\
\hline
\end{tabular}

(1) Média de 2 pastagens na regiáo do Apiaú/FR. Viva acima do solo e a somatório de capim com pequenas ervas e arbusios. Morta acima do solo, compreende todo e qualquer material vegetal acima do solo pertencente a massa do pasto e a massa do antigo uso ilorestal (troncos, por exemplo). (Barbosa \& Feamside, 1996).

(2) Molodologia para obtençáo da Biomassa (Viva e Morta) Acima e Abaixo do Solo.

Da - Método de Expansảo de Volume de Brown \& Lugo (1992) aliado aos latores do ajustes de Foarnside (1992), modificados para massa morla acima e viva abaixo do solo Db - Mótodo de Expansáo de Volume de Brown \& Lugo (1992) aliado aos lalores de ajuslos de Foarnside (1992), modificados para massa moria acima e viva abaixo do solo. Dm-Método de Expansáo de Volume de Brown \& Lugo (1992) aliado aos latores do ajustes de Feamside (1992), modificados para massa morla acima e viva abaixo do solo (foram ponderados clois valores: a) planalto sedimentar Roraima $(10,7 \%)$ e b) montanhosa do Parima $(89,3 \%)$.

Ds - Mótodo de Expansáo de Volume de Brown 8 Lugo (1992) aliado aos fatores de ajustes de Fearnside (1992), modificados para massa morta acima e viva abaixo do solo (toram utilizados dols valores (media simples): a) baixa cadeia de montanha do Complexo Guianense e b) sup. dissec, do Complexo Guianense).

As - Por falta de referéncias locais, utilizou -se o mesmo valor determinado para ON.

ON . Melodo de Expansas le Volume ute Brown \& Lmo valor delerminado para ON SN - Mélodo do Expansáo de Volume de Brown \& Lugo (1992) alliado aos latores de ajustes de Feamside (1992), modificados para massa morta acima e viva abaixo do solo

SO- Por lalta de reforéncias, utilizou-se o valor delerminado para SN. (toi modillcado a partir dos valores obtidos para "La" (RADAM). e comparado aos resultados encontrados por Silva (1993))

LO - Uillizado como a média de irếs valores para compor a biomassa viva e morta acima do solot a) expansáo de volume; b) "Bana Alta" (Tall Arrazon Caalinga). na Venezuela, por Bongers et al. (1985) e c) Caatinga Amazónica, na Venezuela, por Klinge \& Herrera (1983). Para a biomassa abalxo do solo, uilizou-se a média de $10 d 0$ o restanle do grupo, para formar a porcontagem em relaçáo à biomassa viva acima do solo.

Ld. Por lalla de relerências locais, utilizou-se o valor determinado para "Bana Baixa" (Low Amazon Caatinga), na Venezuela, de Bongers el al. (1985)

La . Ottido a partir do trabalho de campo de Cavale delerminado para "Bana Baixa" (Low Amazon Caatinga), na Vonezuela, de Bongers ol al. (1985) dos referidos autores loram ajustados para Peso Seco, sogundo metodologia de Carvalho et al. (1995) o Higuchi et al. (1997). A correçáa de massa de outros componentes loi loito pelas médias oblidas de"outros componentes" de Bongers el al (1985). para "Bana".

$\mathrm{Lg}$. Por falta de referências locais, utllizou-se o valor determinado para "Bana Aberta" (Open Amazon Caatinga), na Venezuela, de Bongers et al. (1985)
$\mathrm{m}$. Estimativa baseada no estrato rasioiro das paisagens Sg. Sp e Tp.

$\mathrm{Sg}$. Biomassa acima do solo (morta e viva) sogundo Barbosa (1998) e, biomassa abaixo do solo, assumida como a média obtida dos resultados encontrados por Castro \& Kautiman (1998). para "campo limpo" o "campo sujo" s 2 m de profundidado, próximo do Brasilia ( 3.78 vezes a massa viva acima do solo)

$\mathrm{Sp}$ (e Sa). Bionassa acima do solo (monta e viva) segundo Barbosa (1998) e, blomassa abaixo do solo, assurnida como a média obtida dos resultados encontrados por Castro \& Kaulliman (1998), para "campo limpo" e "campo sujo" a $2 \mathrm{~m}$ de profundidade, próximo de Brasília (3,78 vezes a massa viva acima do solo)

Tp - Biomassa acima do solo (morta e viva) segundo Barbosa (1998) e. blomassa abaixo do solo, assumida como a média obtida dos resultados encontrados por Castro \& Kaultman (1998), para "cerrada aberto" a "cerrado denso" a $2 m$ de profundidado, próximo do Braslia (2.55 vezes a massa viva acima do solo)

Td (e Ta) - Assumido o valor de Fearnside (s/d) - 29 tha para blomassa acima do solo e, particionando este valor (vivo e morno), pela media dos demais valores de cerrado encontrados na tabela. Para blomassa abaixo do solo, o método lol a masmo adotado para Tp.

Pasiagem - Biomassa viva acima do solo o o o resuliado da média simples de duas amostragens realizadas na região do Apiaú/RA (Barbosa \& Fearnside, 1996) (o valor para biomassa morla acima do solo foi considerado o mesmo do determinado para capoeira - ambos os sistemas sảo provenientes de desmatamonto: por sor uma paisagem resultante de desmatamento, a biomassa abaixo do solo loi considerada como uma média da biomassa abaixo do solo de lodos os sistemas florestals)

Capoeira - Biomassa acima do solo é assumida como o valor determinado para "Capoelra" do 6-7 anos na regiấ do Aplaú/RR (Fearnside el al.. sd). (blomassa morta fol considerada como "romanescente da floresta original" no mesmo estudo e, biomassa abaixo do solo é a mesma relaçáo descrinta para pastagem).

Cultivos Agricolas . Assumido como o mesmo apresentado por Fearnside (1997a) para "larmland", lo valor para biomassa morta acima do solo fol considerado como uma medla simples entre a massa morta acima do solo de pastagens e capoeiras o,

a biomassa viva de novos desmalamentos - lodos considerados ambientes Iranstormados)

Desmatamento do Perlodo - Considerado como a biomassa presente no momento da derrubada. Fol determinado como uma ponderaçăo dos valores determinados para Ds, ON. Fs, Lo - As. A biomassa monta acima do solo é o conjunto desto cálculo mais o litter (fino e grosso) pré-existente. 
do solo) destes sistemas variou de 13$95 \mathrm{t} / \mathrm{ha}$ dependendo da proporção de árvores presente em cada ambiente.

A estimativa da biomassa préexistente nos sistemas antrópicos foi realizada da seguinte forma: (a) pastagens: utilizamos a média simples entre duas pastagens ( 7 e 9 anos de idade) estudadas na região do Apiaú, em Roraima, por Barbosa \& Fearnside (1996). No resultado de biomassa viva acima do solo, consideramos o somatório da massa do capim e da massa das pequenas ervas nãolenhosas. Para a biomassa morta acima do solo, consideramos o mesmo estudo e determinamos a média de toda a massa dos residuos florestais encontrados nas duas pastagens. Para a biomassa abaixo do solo, consideramos as proporções médias existentes nos outros sistemas transformados para determinar a porcentagem em relação à massa viva acima do solo; (b) capoeiras (florestas secundárias): utilizamos os resultados obtidos por Fearnside et al. (sd) em uma derrubada de capoeira com 6 anos de idade na região do Apiaú, Roraima; (c) cultivos agrícolas: estimamos como o mesmo valor determinado por Fearnside (1997a) para biomassa viva acima do solo e, admitimos o mesmo resultado proporcional (viva/morta) para biomassa morta acima do solo nas pastagens da região do Apiaú, em Roraima; (d) desmatamento 1998: consideramos como a biomassa presente no ato da derrubada (antes da queimada); este valor foi estimado como uma ponderação (em função da área) de todos os outros tipos florestais que sofrem a ação do desmatamento em Roraima. O resultado para biomassa total nestes sistemas foi de $89 \mathrm{t} / \mathrm{ha}$ (pastagens), $166 \mathrm{t} / \mathrm{ha}$ (capoeiras), $69 \mathrm{t} /$ ha (cultivos agrícolas) e $314 \mathrm{t} / \mathrm{ha}$ (áreas recentemente desmatadas).

\section{Biomassa Arbórea Florestal Morta pela Ação do Fogo}

Para o levantamento da biomassa morta nas unidades fitofisionômicas florestais realizamos investigações pós-fogo em três regiões atingidas pelos incêndios: (a) Apiaú/Ribeiro Campos, (b) Trairão/Tepequém e (c) Paredão, todos dentro da físionomia ON (área de tensão ecológica e contato floresta ombrófila / floresta sazonal), que foi a mais atingida dos sistemas florestais. Para as espécies arbóreas acima de $10 \mathrm{~cm}$ de diâmetro à altura do peito (DAP), estabelecemos sete transectos de $750 \mathrm{~m}^{2}$ cada um, sendo três na primeira localidade, três na segunda e um na terceira. Cada transecto foi dividido em 6 quadras de $125 \mathrm{~m}^{2}(5 \mathrm{~m} \times 25 \mathrm{~m})$, separadas por uma distância de $20 \mathrm{~m}$. Em cada quadra nós medimos o DAP de todos os indivíduos mortos (câmbio seco e/ou copa com folhas secas) e aplicamos a fórmula geral de determinação de biomassa (peso fresco) de árvores de florestas tropicais indicada por Carvalho et al. (1995) e Higuchi et al. (1997, 1998). O valor foi ajustado para peso seco $(\mathrm{t} / \mathrm{ha})$ seguindo as recomendações dos referidos autores. Com isto, nós alcançamos o resultado 
de $5,8 \mathrm{t} /$ ha para os 2.173 indivíduos mortos com DAP abaixo de $10 \mathrm{~cm}$ e $17,4 \mathrm{t} / \mathrm{ha}$ para os 46 indivíduos mortos com DAP acima de $10 \mathrm{~cm}$ (Tab. 4).

Estes valores são similares aos $16,1 \mathrm{t} /$ ha determinados para individuos mortos acima de $10 \mathrm{~cm}$ de DAP, apresentado por Santos et al. (1998) na região do Apiaú e, com o levantamento de mortalidade de indivíduos que as equipes do IBAMA realizaram em 5 regiões afetadas pelos incêndios; média de 50 indivíduos mortos/ha com DAP acima de $10 \mathrm{~cm}$, incluindo palmeiras (IBAMA, 1998). Contudo, a variação dos valores distribuídos pelas classes diamétricas e localidades reflete uma grande variação entre as regiões avaliadas, apesar de todas serem classificadas na mesma categoria florestal (ON). Em relação a outros estudos realizados em situações semelhantes, nosso valor porcentual para mortalidade de indivíduos $(7,9 \%)$ é 5,5 vezes inferior aos $44 \%$ determinado para áreas queimadas de florestas derivadas de corte seletivo em Paragominas (Holdsworth \& Uhl, 1997) e, 7,6 vezes menor que os $60,3 \%$ de mortalidade média encontrada 8 meses do pós-fogo em 4 localidades também do município de Paragominas, Pará, em áreas de floresta já pertubadas (Kauffman, 1991). Em termos de biomassa arbórea total morta acima do solo, nossos valores representam menos da metade das 50 t/ha de massa morta por um incêndio leve (área queimada apenas uma vez) constatado ao sul da cidade de Tailândia, Pará (Cochrane \& Schulze, 1999). Embora

Tabela 4. Mortalidade de indivíduos ( $\mathrm{n} / \mathrm{ha}$ ) e de biomassa ( $\mathrm{t} / \mathrm{ha}$ ) arbórea acima do solo determinada por três estudos realizados em Roraima no pós-incêndio.

\begin{tabular}{|c|c|c|c|c|c|c|c|c|c|}
\hline \multirow{3}{*}{ Parâmetros } & \multicolumn{6}{|c|}{ Classes Diamétricas Simplificadas $(\mathrm{cm})$} & \multicolumn{2}{|c|}{$\begin{array}{l}\text { Média Arbórea } \\
\text { Acima Solo }\end{array}$} & \multirow{3}{*}{ Fonte } \\
\hline & \multicolumn{2}{|c|}{$<5$} & \multicolumn{2}{|c|}{$5-10$} & \multicolumn{2}{|c|}{$>10$} & \multirow{2}{*}{$\begin{array}{l}\text { Ind. } \\
\text { n/ha }\end{array}$} & \multirow{2}{*}{$\begin{array}{l}\text { Bio. } \\
\text { tha }\end{array}$} & \\
\hline & $\mathrm{n} / \mathrm{ha}$ & tha & $\mathrm{n} / \mathrm{ha}$ & t/ha & $\mathrm{n} / \mathrm{ha}$ & tha & & & \\
\hline Ind/Bio Total (1) & 2120 & 5,6 & 307 & 19,9 & 58,5 & 219,7 & 3011 & 245,2 & \\
\hline Mortas & 1933 & 3,0 & 240 & 2,8 & 46 & 17,4 & 2219 & 23,3 & Este Estudo \\
\hline (\%) mortalidade & 91,2 & 54,2 & 78,3 & 14,1 & 7,9 & 7,9 & 73,7 & 9,5 & \\
\hline Ind/Bio Total (2) & & & 340 & & 425 & & & & \\
\hline Mortas & & & 122 & 3,0 & 68 & 16,1 & & & $\begin{array}{l}\text { Santos et al. } \\
\text { (1998) }\end{array}$ \\
\hline (\%) mortalidade & & & 35,9 & & 16,0 & & & & \\
\hline Ind/Bio Total & & & & & 616 & & & & \\
\hline Mortas & & & & & 50 & & & & $\begin{array}{l}\text { IBAMA } \\
\text { (1998) }\end{array}$ \\
\hline (\%) mortalidade & & & & & 8,1 & & & & \\
\hline
\end{tabular}

(1) Para DAP > ou $=10 \mathrm{~cm}$; localidades do Apiaú//hibeiro Campos. TrairăorTepequém e Paredáo? Para DAP $<10 \mathrm{~cm}$; locallidade do Apiaú/Ribeiro Campos (2) Pegiă do Apiaúmuuçiai

(3) Inclui palmeiras. Avaliaçấo das áreas do arco do incéndio lormado pelas regióes do Roxinho, Caracará, Apiaú. Pacaraims e Trairăo. 
hajam diferenças entre as estruturas florestais naturais e aquelas já pertubadas pela ação antrópica, as comparações acima relatadas sugerem que uma avaliação pós-fogo nas circunstâncias de Roraima não deveria ser realizada apenas para investigar os impactos instantâneos que o incêndio provoca na floresta. Dramática troca de biomassa e número de individuos mortos, mesmo em sistemas pouco atingidos, devem ser observados e comparados com melhor exatidão em investigações de longo prazo.

A biomassa arbórea morta abaixo dos $10 \mathrm{~cm}$ de DAP foi estimada através da contabilização dos indivíduos (mortos e vivos) em 2 transectos de $375 \mathrm{~m}^{2}$ cada (3 quadras de $125 \mathrm{~m}^{2}$ ) estabelecidos na localidade do Apiaú/ Ribeiro Campos. Os indivíduos foram divididos em duas categorias: (a) menor que $5 \mathrm{~cm}$ de DAP (incluindo todas as mudas e rebentos de diferentes alturas) e (b) entre $5-10 \mathrm{~cm}$ de DAP. O cálculo da biomassa destas duas categorias foi estimada em função da proporção existente entre o número de individuos presentes (mortos e vivos) e os valores determinados para biomassa abaixo de $10 \mathrm{~cm}$ de DAP encontrados nas estimativas realizadas para biomassa total por tipologia florestal, descrita acima.

\section{Formação de Carvão}

O carvão formado pela passagem do fogo nos sistemas florestais primários foi estimado pelo estabelecimento de 20 quadras de $1 \mathrm{~m}^{2}$ cada, na localidade do Apiaú/Ribeiro Campos. As quadras foram distri- buídas da seguinte forma: (a) 11 onde o fogo foi considerado de alta intensidade, (b) 5 em ambientes com danos de média intensidade e (c) $4 \mathrm{em}$ ambientes com danos de baixa intensidade. Em cada quadra foram coletadas todas as peças de carvão que se encontravam sobre o solo. Foram determinados o peso úmido e, posteriormente, o peso seco (em estufa a $105^{\circ} \mathrm{C}$ até peso constante) por unidade de área. Nós ponderamos os valores encontrados por intensidade de queima para se estabelecer um resultado médio para toda a área queimada e por bloco de queima. $\mathrm{O}$ resultado médio foi de $229,7 \mathrm{~kg}$ de carvão formados por hectare atingido pelo incêndio nas áreas florestais. (Tab. 5). Este valor é, em média, $0,089-0,104 \%$ da biomassa total acima do solo existente nas florestas (densa e não-densa) de Roraima e, difere substancialmente dos valores encontrados para queima de sistemas transformados como pastagens $(0,025 \%$ a $0,038 \%)$, capoeiras $(0,006 \%$ a $0,020 \%)$ e desmatamentos recentes $(0,019 \%)$ (Barbosa \& Fearnside, 1996; Fearnside, 1997a;b; Fearnside et al., sd).

\section{Eficiência de Queimada}

A eficiência de queimada para as categorias vegetais que compoem as fisionomias florestais que sofreram a ação do fogo foi decomposta em três grupos: (a) litter fino: folhas e gravetos inferiores a $2 \mathrm{~cm}$ de diâmetro caídos sobre o chão da floresta, (b) litter grosso: troncos e galhos mortos 
Tabela 5. Formação de carvão (t/ha) superficial decorrente dos incêndios em sistemas florestais de Roraima (1997/98), por zona de intensidade e por bloco de queima

\begin{tabular}{|c|c|c|c|c|c|}
\hline \multirow{2}{*}{$\begin{array}{l}\text { Categoria de } \\
\text { Intensidade de } \\
\text { Queima Florestal }\end{array}$} & \multirow{2}{*}{$\begin{array}{c}\text { Média Simples } \\
\text { por Intensidade } \\
\text { (kg/ha) }\end{array}$} & \multicolumn{4}{|c|}{ Área Efetivamente Queimada dentro de Cada Bloco (2) } \\
\hline & & $\begin{array}{c}\text { Bloco } 1 \\
\text { (km2) }\end{array}$ & $\begin{array}{c}\text { Bloco } 2 \\
\text { (km2) }\end{array}$ & $\begin{array}{c}\text { Bloco } 3 \\
\text { (km2) }\end{array}$ & Total \\
\hline $\operatorname{ALTA}(1)$ & 258,7 & 1208 & 5278 & 2702 & 9817 \\
\hline MÉDIA & 51,3 & 793 & 459 & 235 & 1487 \\
\hline BAIXA & 9,8 & 51 & 27 & 11 & 90 \\
\hline $\begin{array}{l}\text { Média Ponderada } \\
\text { por Bloco (kg de } \\
\text { carvão/ha) }\end{array}$ & - & 172,3 & 241,0 & 241,2 & 229,7 \\
\hline
\end{tabular}

(1) Ponderamos o valor da zona de alta intensidade de queima porque 6 quadras foram coletadas em locais de terra-firme (173,9 $\mathrm{kg} / \mathrm{ha} \mathrm{em} 84 \%$ da área afetada e 5 em locais de pé-de-serra $(707,3 \mathrm{~kg} / \mathrm{ha}$ ou $16 \%$ da área afetada).

(2) O valor aqui utilizado foi o determinado pelo método das zonas de impacto do fogo.

sobre o solo com diâmetro acima de $2 \mathrm{~cm}$ e (c) outros componentes: demais categorias vegetais que não se enquadram dentro de litter e também não são árvores. As estimativas percentuais de eficiência de queimada foram baseadas na média das medidas realizadas por Uhl et al. (1988) em uma queima experimental em São Carlos (Venezuela) e com os dados das equipes das localidades do Trairão e do Roxinho que compunham o grupo do IBAMA que realizou o levantamento terrestre (IBAMA, 1998). Os maiores e os menores valores foram distribuídos entre as zonas de intensidade de queima florestal e, em média, se estabeleceram entre $4,5 \%$ para o litter grosso na baixa intensidade e, $97,6 \%$ para o litter fino na alta intensidade (Tab. 6). Para as categorias vegetais que compõe as savanas, foram utilizados os dados dos estudos que R.I.B. esta realizando desde 1994 nas áreas abertas locais. Os valores foram aglutinados em uma única categoria de intensidade de queima e variaram de $28 \%$ a $94,6 \%$, dependendo da classe de biomassa a que se reportava. Para ambientes antrópicos os números se estabeleceram entre $11,9 \%$ e $97,6 \%$.

\section{Concentração de Carbono}

A concentração de carbono (\% C) nas categorias vegetais de sistemas florestais foi estimada através das medidas realizadas por Barbosa \& Fearnside (1996) e Fearnside et al. (sd) em peças de madeira e outros elementos florestais encontrados em pastagens e capoeiras da região do Apiaú em Roraima. Para a determinação da concentração em categorias componentes das savanas, nós estamos utilizando os resultados obtidos por R.I.B. em seus estudos sobre emissão de gases pela queima e decomposição de savanas em Roraima. Os resultados variaram de 
Tabela 6. Eficiência de queimada (\%) por zona de intensidade de queima (florestal) e por tipo paisagístico, decorrente dos incêndios ocorridos em Roraima (1997/98).

\begin{tabular}{|c|c|c|c|c|c|c|c|c|c|c|}
\hline \multirow{2}{*}{ Categoria } & \multirow{2}{*}{ Código } & \multicolumn{3}{|c|}{ Litter Fino } & \multicolumn{3}{|c|}{ Litter Grosso } & \multicolumn{3}{|c|}{ Outros Componentes } \\
\hline & & Baixa & Média & Alta & Baixa & Média & Alta & Baixa & Média & Alta \\
\hline $\begin{array}{l}\text { Floresta (Densa } \\
\text { e Năo Densa) (1) }\end{array}$ & $\begin{array}{l}\text { Todas as } \\
\text { Tipologias }\end{array}$ & 69,3 & 83,4 & 97.6 & 4,5 & 39,2 & $.73,8$ & 4,5 & 28,0 & 51,5 \\
\hline \multirow[t]{7}{*}{ Não Florestal (2) } & Ld-0 & $\cdot$ & $\cdot$ & 83,4 & $\cdot$ & - & 39,2 & - & - & 28,0 \\
\hline & $\mathrm{Lg}-0$ & $\cdot$ & - & 85,5 & $\cdot$ & - & 22,6 & - & $\cdot$ & 93,2 \\
\hline & $\mathrm{rm}-0$ & $\cdot$ & - & 85,5 & $\cdot$ & - & 22,6 & $\cdot$ & - & 93,2 \\
\hline & $\mathrm{Sg}-0$ & - & $\cdot$ & 81,9 & $\cdot$ & - & 18,6 & - & $\cdot$ & 90,2 \\
\hline & Sp-0 & - & - & 84,2 & $\cdot$ & - & 22,9 & - & - & 94,8 \\
\hline & Td-3 & - & $\cdot$ & 85,5 & $\cdot$ & - & 22,6 & - & - & 93,2 \\
\hline & Tp-3 & $\cdot$ & · & 90,4 & $\cdot$ & - & 26,3 & $\cdot$ & $\cdot$ & 94,6 \\
\hline \multirow[t]{4}{*}{ Antrópico } & Pastagem & - & - & 45,6 & , & , & 11,9 & - & . & 82,1 \\
\hline & Capoeira & - & $\cdot$ & 91,3 & $\cdot$ & - & 31,6 & - & - & 80,0 \\
\hline & Cultivo Agricola & - & - & 91,3 & - & - & 21,8 & - & - & 81,1 \\
\hline & Desmatamento (3) & - & - & 97,6 & - & - & 30,0 & $\cdot$ & - & 75,7 \\
\hline
\end{tabular}

(1) Consideramos uma média geral para todos os tipos de sistemas florestais.

(2) Para os sistemas não florestais, nós levamos em consideraçâo os valores determinados para as savanas locais e estimamos para as regiōes oligotróficas em funçăo da massa presente em cada sistema.

(3) A eficiência de combustáo para litter grosso e outros componentes em "desmatamento" foi considerada como o mesmo valor observado em Altarnira por Fearnside et al. (1999). Para litter fino, utilizamos a média simples dos resultados encontrados pelos mesmos autores em Manaus e Altamira.

\section{$32,3 \%$ C para litter de savana} gramineo-lenhosa até $64,4 \% \mathrm{C}$ para carvão encontrado em diferentes ambientes (Tab. 7).

\section{Destino do Carbono Afetado pelo Fogo}

A massa total de carbono afetada pelos incêndios em Roraima entre 1997/ 98 foi de 42,58 milhões de toneladas de carbono (t C) e seguiu três caminhos diferentes: (a) emitido instantânemente para a atmosfera pela ação da combustão nos componentes vegetais: 19,73 milhões de t $\mathrm{C}$ ou $46,3 \%$ do total, (b) estocado na forma de carvão sobre o solo dos sistemas atingidos: 0,52 milhões de t C ou 1,2\% e (c) material vegetal morto pelo fogo (principalmente árvores) em processo de decomposição:
22,33 milhões t $\mathrm{C}$ ou 52,4\% (Tab. 8). Do total de carbono afetado, $73,9 \%(31,47$ milhões de t C) foram atribuidos aos sistemas florestais primários que sofreram a ação do fogo. Os sistemas de menor contribuição foram os oligotróficos (outros sistemas nãoflorestais) com $2,0 \%$ do total afetado $(0,84$ milhões de t $\mathrm{C})$.

\section{Emissões Brutas de Gases do Efeito Estufa}

Para estimar a quantidade de gases do efeito estufa $\left(\mathrm{CO}_{2}, \mathrm{CH}_{4}, \mathrm{CO}\right.$, $\mathrm{N}_{2} \mathrm{O}$, NOx e NMHC) emitidos para a atmosfera, adotamos o método de Fearnside (1997a;b), utilizando o potencial de aquecimento global do Intergovernamental Panel on Climate Change (IPCC) em um horizonte de 
Tabela 7. Concentração de carbono média (\% C) presente nos principais componentes dos sistemas ecológicos de Roraima.

\begin{tabular}{|c|c|c|c|c|c|}
\hline Categoria & Código & $\begin{array}{l}\text { Árvores Mortas } \\
\text { (acima e abaixo } \\
\text { do solo) }\end{array}$ & $\begin{array}{c}\text { Litter } \\
\text { (fino+grosso) }\end{array}$ & $\begin{array}{l}\text { Outros } \\
\text { Componenes }\end{array}$ & $\begin{array}{l}\text { Carvão (Estoque } \\
\text { de Longo Prazo) }\end{array}$ \\
\hline $\begin{array}{l}\text { Floresta (Densa } \\
\text { e Não Densa) }\end{array}$ & $\begin{array}{l}\text { Todas as } \\
\text { Tipologias }\end{array}$ & 48,2 & 39,8 & 48,2 & 64,4 \\
\hline \multirow[t]{7}{*}{ Não Florestal } & Ld -0 & 48,2 & 39,8 & 48,2 & 64,4 \\
\hline & $\operatorname{Lg} \cdot 0$ & 46,1 & 38,3 & 39,6 & 64,4 \\
\hline & $\mathrm{rm}=0$ & 46,1 & 38,3 & 39,6 & 64,4 \\
\hline & $\mathrm{Sg}=0$ & 46,1 & 32,3 & 35,8 & 64,4 \\
\hline & $S p-0$ & 46,1 & 40,6 & 41,6 & 64,4 \\
\hline & Td -3 & 46,1 & 38,3 & 39,6 & 64,4 \\
\hline & Tp-3 & 46,1 & 42,1 & 41,2 & 64,4 \\
\hline \multirow[t]{4}{*}{ Antrópico } & Pastagem & 44,5 & 47,8 & 43,8 & 64,4 \\
\hline & Capoeira & 44,5 & 42,9 & 45,5 & 64,4 \\
\hline & Cultivo Agrícola & 44,5 & 45,4 & 44,6 & 63,8 \\
\hline & Desmatamento & 44,5 & 45,4 & 44,6 & 63,8 \\
\hline
\end{tabular}

Tabela 8. Destino do carbono afetado pela queima de sistemas vegetais em Roraima (1997/98).

\begin{tabular}{|c|c|c|c|c|c|c|c|c|}
\hline \multirow{2}{*}{ Sistema } & \multicolumn{2}{|c|}{ Combustão (1) } & \multicolumn{2}{|c|}{ Carvão } & \multicolumn{2}{|c|}{ Decomposição } & \multicolumn{2}{|c|}{ Total } \\
\hline & $\left(10^{6} t\right)$ & $(\%)$ & $\left(10^{6} t\right)$ & $(\%)$ & $\left(10^{6} t\right)$ & $(\%)$ & $\left(10^{6} t\right)$ & $(\%)$ \\
\hline Florestas & 12,64 & 64,0 & 0,18 & 34,4 & 18,66 & 83,5 & 31,47 & 73,9 \\
\hline Savanas & 3,10 & 15,7 & 0,0022 & 0,4 & 2,77 & 12,4 & 5,87 & 13,8 \\
\hline $\begin{array}{l}\text { Outros Sistemas } \\
\text { Não Florestais }\end{array}$ & 0,27 & 1,4 & 0,0008 & 0,2 & 0,58 & 2,6 & 0,84 & 2,0 \\
\hline Antrópicos & 3,73 & 18,9 & 0,34 & 65,0 & 0,33 & 1,5 & 4,40 & 10,3 \\
\hline Total & 19,73 & 46,3 & 0,52 & 1,2 & 22,33 & 52,4 & 42,58 & 100 \\
\hline
\end{tabular}

(1) Combustăo= emissăo instantânea no ato da passagem do fogo; carvắo= carvẵo formado pela combustăo incompleta do material vegetal; decomposiçăo= material que morreu e entrou em processo de decomposiçăo após a passagem do fogo.

tempo de 100 anos (Schimel et al., 1995), sem os descontos de sequestros de carbono da atmosfera pela biota terrestre. Este método diferencia dois cenários de emissão de gases-traço diferentes de $\mathrm{CO}_{2}$ : (a) baixo cenário (baixa emissão de gases-traço) e (b) alto cenário (alta emissão de gases-traço). Por ser um fato novo, não produzimos nenhuma estimativa baseada na liberação líquida de gases pela decomposição do material vegetal morto nos incêndios ou mesmo pelo sequestro de carbono por sumidoros artificiais ou naturais. Portanto, nossos cálculos não se reportam ao balanço anual do evento ou às emissões líquidas comprometidas, mas sim a emissão 
bruta de gases estimada a partir do carbono emitido instantâneamente por combustão no ato da passagem do fogo.

O total de gases emitidos, equivalente a $\mathrm{CO}_{2}$, foi de 22,1-25,4 milhões de toneladas, dependendo do cenário de baixa e alta emissão de gases-traço diferentes de $\mathrm{CO}_{2}$ (Tab. 9). Isto corresponde a 6,1-7,0 milhões de t $\mathrm{C}$ equivalente a $\mathrm{CO}_{2}$. A maior parte destas emissões $(68,1-78,1 \%)$ foi atribuída aos sistemas de floresta primária impactados pelo fogo $(4,0-$ 4,7 milhões de toneladas de $\mathrm{C}$ equivalente a $\mathrm{CO}_{2}$ ), seguindo-se os ambientes antrópicos (1,2-1,4 milhões), as savanas ( $0,8-0,9$ milhões) e os outros sistemas não-florestais $(0,1$ milhões). Mesmo assumindo uma redução de $25-34 \%$ nas estimativas anteriores de biomassa por unidade de área florestal, nosso valor médio total (6,55 milhões de $\mathrm{t} \mathrm{C}$ equivalente a $\mathrm{CO}_{2}$ ) equivale a 1,5 vezes o calculado por Fearnside (1997b) para Roraima, considerando todas as emissões liquidas comprometidas para $o$ ano de 1990 e todas as fontes/sumidouros de carbono daquele ano (4,3-4,4 milhões de $\mathrm{C}$ equivalente ao $\mathrm{CO}_{2}$ ).

\section{CONCLUSÃO}

Incêndios florestais provocados por queimadas antrópicas na Amazônia em anos de grande seca como o do episódio "El Niño" de Roraima em 1997/98, podem provocar a emissão de grandes quantidades de gases do efeito estufa para a atmosfera. Nossos resultados indicaram que as florestas primárias impactadas pelo fogo em 1997/98 emitiram 4,0-4,7 milhões de toneladas de $\mathrm{C}$ equivalente ao $\mathrm{CO}_{2}$. Levando em consideração que várias queimadas penetram em florestas anualmente por toda a Amazônia, é possivel prever que as estimativas de carbono liberado anualmente pela região por distúrbios florestais sejam maiores do que os 0,3 x $109 \mathrm{Gt} /$ ano atualmemnte assumidos (Fearnside, 1997a;b; Nepstad et al., 1999b). A pressão antrópica, a ampliação das áreas pertubadas por desmatamentos, pastagens, cultivos agrícolas e exploração florestal por corte seletivo nos últimos 20 anos em Roraima, foram a fonte de ignição que provocou a queima de 38.144-40.678 $\mathrm{km}^{2}$ de diferentes ambientes, destacando-se os 11.394-13.928 km² de florestas primárias atingidas pelo fogo. O evento "El Niño" apenas maximizou os efeitos do aumento da atividade humana em sistemas florestais de Roraima nos últimos anos, indicando que os riscos de ocorrerem incêndios desta magnitude por toda a Amazônia podem ser maiores do que aquele imaginado há pouco tempo.

\section{AGRADECIMENTOS}

Ademir J. dos Santos, Antônio C. Catâneo e Jaime França, do IBAMA, Carlo Zacquini da Comissão PróYanomami (CCPY/RR) e o Conselho Indigena de Roraima (CIR) gentilmente cederam horas de vôo de seus projetos para facilitar as medições de área queimada via aérea. Rogério Gribel (INPA), Jeanine Felfili 
Tabela 9. Emissão bruta de gases do efeito estufa (por combustão), provenientes dos incêndios em Roraima entre 1997/98, com o total dos gases em equivalência ao $\mathrm{CO}_{2}$ em um horizonte de tempo de 100 anos.

\begin{tabular}{|c|c|c|c|c|c|c|c|c|c|c|c|c|}
\hline \multirow[t]{2}{*}{ Gas } & \multirow[t]{2}{*}{ GwP } & \multirow[t]{2}{*}{$\begin{array}{l}\text { Florestas } \\
\text { Intactas }\end{array}$} & Savanas & $\begin{array}{l}\text { Out Sist. N } \\
\text { Horestais }\end{array}$ & Antrópicos & Total & $\begin{array}{l}\text { Florestas } \\
\text { Intaclas }\end{array}$ & Savanas & $\begin{array}{l}\text { Out. Sist. N. } \\
\text { floteslais }\end{array}$ & Antropicos & Total & $\begin{array}{l}\text { Contribuicl } \\
\text { cadagąs }\end{array}$ \\
\hline & & & \multicolumn{3}{|c|}{ 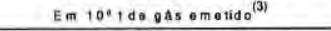 } & \multicolumn{7}{|c|}{ Em 1001 de gats equivalente a $\mathrm{CO}_{2}$} \\
\hline $\mathrm{CO}$ & 1 & 10.65 & 3,60 & 0.28 & 3,65 & 18.24 & 10.65 & 3.66 & 0.28 & 3,65 & 18,24 & 78.71 \\
\hline $\mathrm{CH}$, & 24,5 & 0.15 & 0,02 & 0.00 & 0.05 & 0.21 & 3.06 & 0,32 & 0.03 & 1.05 & 4,45 & 19.22 \\
\hline $\mathrm{co}$ & 0 & 1.13 & 0.58 & 0.04 & 0.39 & 2.14 & 0.00 & 0.00 & 0.00 & 0.00 & 0.00 & 0.00 \\
\hline $\mathrm{N}, \mathrm{O}$ & 320 & 0.00 & 0.00 & 0.00 & 0.00 & 0,002 & 0,30 & 0,08 & 0.01 & 0,10 & 0,48 & 2.07 \\
\hline No, & 0 & 0.04 & 0,01 & 0.00 & 0.01 & 0.06 & 0.00 & 0.00 & 0.00 & 0.00 & 0.00 & 0.00 \\
\hline NMHC & 0 & 0.16 & 0.04 & 0.00 & 0.05 & 0.25 & 0,00 & 0.00 & 0.00 & 0.00 & 0.00 & 0.00 \\
\hline \multirow{2}{*}{\multicolumn{3}{|c|}{$\begin{array}{l}\text { Total do gás aquivalente a } \mathrm{CO}_{2} \\
\mathrm{C} \text { equivalente a } \mathrm{CO}_{2}\end{array}$}} & & & & & 14,0 & 4.1 & 0.3 & 4,8 & 23.2 & \\
\hline & & & & & & & 3.9 & 1,1 & 0.1 & 1,3 & 6,4 & \\
\hline \multicolumn{13}{|c|}{ Allo conario (2) } \\
\hline \multirow[t]{2}{*}{ Gas } & $\begin{array}{l}\text { GWP } \\
\text { (1) }\end{array}$ & $\begin{array}{l}\text { Florestas } \\
\text { Intacias }\end{array}$ & Savanas & $\begin{array}{l}\text { Out. Sisi. N. } \\
\text { Horestais }\end{array}$ & Antropicos & Tolal & $\begin{array}{l}\text { Florestas } \\
\text { Intaclas }\end{array}$ & Savanas & $\begin{array}{l}\text { Out. Sist. N. } \\
\text { Horestais }\end{array}$ & Antropicos & Total & $\begin{array}{l}\text { Contribuici } \\
\text { cada gas }\end{array}$ \\
\hline & & & \multicolumn{3}{|c|}{ Em $10 * 180 \mathrm{gas}$ emetido ${ }^{(3)}$} & \multicolumn{7}{|c|}{ Em $10 \% 1$ de $\mathrm{gas}$ equivalente a $\mathrm{CO}_{2}$} \\
\hline $\mathrm{CO}$ & 1 & 10.65 & 3,66 & 0.28 & 3.65 & 18.24 & 10.65 & 3,66 & $0.2 \mathrm{~B}$ & 3,65 & 18.24 & 68.81 \\
\hline $\mathrm{CH}$, & 24,5 & 0.24 & 0,03 & 0.00 & 0.08 & 0,35 & 5,10 & 0,56 & 0.04 & 1,74 & 7.44 & 28,08 \\
\hline $\mathrm{co}$ & a & 2,26 & 0,78 & 0,06 & 0.78 & 3,80 & 0.00 & 0,00 & 0.00 & 0,00 & 0.00 & 0.00 \\
\hline $\mathrm{N}_{\mathrm{p}} \mathrm{O}$ & 320 & 0.00 & 0,00 & 0.00 & 0.00 & 0,003 & 0.53 & 0.10 & 0.01 & 0.18 & 0.82 & 3.11 \\
\hline NO, & 0 & 0.06 & 0,01 & 0,00 & 0.02 & 0,10 & 0,00 & 0,00 & 0,00 & 0,00 & 0,00 & 0.00 \\
\hline NMHC & $a$ & 0.16 & 0.04 & 0.00 & 0.05 & 0,25 & 0.00 & 0,00 & 0.00 & 0.00 & 0.00 & 0.00 \\
\hline \multirow{2}{*}{\multicolumn{3}{|c|}{$\begin{array}{l}\text { Totalde gas equivalente a } \mathrm{CO}_{2} \\
\mathrm{C} \text { equivatente a } \mathrm{CO} \text {. }\end{array}$}} & & & & & 16.3 & 4.3 & 0.3 & 5.6 & 26.5 & \\
\hline & & & & & & & 4,5 & 1.2 & 0.1 & 1,5 & 7.3 & \\
\hline
\end{tabular}

(1) GWP=Potencial de aquecimento global (é um valor determinado pelo IPCC para dar peso aos gases-traço em um horizonte de tempo de 100 anos) (2) Os Baixo e Alto Cenários săo relativos ao peso dado ao gases-traço dilerentes de CO2.

(3) Os fatores de emissão que determinam a fraçâo de carbono que corresponde a uma quantidade qualquer de gás emitida foram retirados de: (a) tlorestas e desmatamentos: Fearnside (1997a) e IPCC/OECD (1997); (b) savanas e outros sistemas năo-florestais: Hurst et al. (1996) e IPCC/OECD (1994).

(UnB), Ary T. O. Filho (U. F. de Lavras), Marco Aurélio Fontes (U. F. de Lavras) e Marcelo T. Nascimento (UENF), se colocaram a disposição cedendo gentilmente seus dados originais de campo para comparações com nossa base de cálculos de mortalidade dos indivíduos nos sistemas florestais. Viriato de Souza Cruz (ZEE/Roraima), operacionalizou todas as medidas de área queimada com a cessão da utilização dos equipamentos e "softwares" à disposição da Secretaria Executiva do ZEE/Roraima. Thelma Krug e João Roberto dos Santos, ambos do INPE, colaboraram com trocas de informações que facilitaram o ajuste final das áreas atingidas pelos incêndios. Sebastião Pereira do Nascimento e Herundino
Ribeiro do Nascimento (Convênio INPA/GERR), colaboraram com as atividades de campo.

\section{Bibliografia citada}

Barbosa, R.I. 1993. Ocupação humana em Roraima. II . Uma revisão do equivoco da recente politica de desenvolvimento e o crescimento desordenado. Bol. Mus. Par: Emilio Goeldi (S. Antrop.), 9(2): 177-197.

Barbosa, R.I. 1997. Distribuição das Chuvas em Roraima. In: Barbosa, R.I.; Ferreira, E.; Castellón, E. (eds.). Homem, Ambiente e Ecologia no Estado de Roraima. INPA, Manaus. p. 325-335.

Barbosa, R.I. 1998a. Avaliação preliminar da área dos sistemas naturais $e$ agroecossistemas atingida por incêndios no Estado de Roraima (01.12.1997 a 31.03.1998). Instituto Nacional de Pesquisas da Amazônia / Núcleo de 
Pesquisas de Roraima (INPA/NPRR), 02.04.1998. Boa Vista 18p. (manuscrito).

Barbosa, R.I. 1998b. Avaliação da área dos sistemas naturais e agroecossistemas atingida pelo fogo no Estado de Roraima (01.12.97 a 30.04.98). Instituto Nacional de Pesquisas da Amazônia / Núcleo de Pesquisas de Roraima (INPA/ NPRR), 16.05.98. Boa Vista. $21 \mathrm{ptanexos.} \mathrm{(manuscrito).}$

Barbosa, R.I. 1998c. Incêndios de Roraima (1997/98): Área queimada, biomassa, mortalidade e formação de carvão nas principais fitofisionomias. Instituto Nacional de Pesquisas da Amazônia / Núcleo de Pesquisas de Roraima (INPA/ NPRR), 04.12.98. Boa Vista 20p. (manuscrito).

Barbosa, R.I.; Fearnside, P.M. 1996. Pasture burning in Amazonia: Dynamics of residual biomass and storage and release of abouveground carbon. Journal of Geophysical Research, 101(D20): 25847-25857.

Bongers, F.; Engelen, D. ; Klinge, H. 1985. Phytomass structure of natural plant communities on spodosols in southern Venezuela: the Bana woodland. Vegetatio 63: 13-34.

Braga, I, 1998. FHC assume incêndio de Roraima. Amazonas em Tempo, Manaus, 09 de julho de 1998. p. B4.

Brown, S, ; Lugo, A. 1992. Aboveground biomass estimates for tropical moist forests of the Brazilian Amazon. Interciencia 17(1): 8-18.

Carvalho, J.A.; Santos, J.M.; Santos, J.C.; Leitão, M.M. ; Higuchi, N. 1995. A tropical rainforest clearing experiment by biomass burning in the Manaus region. Atmospheric Environment, 29(17): 2301-2309.

Castro, E.A. ; Kauffman, J.B. 1998. Ecosystem structure in the Brazilian Cerrado: a vegetation gradient of aboveground biomass, root mass and comsuption by fire. Journal of Tropical Ecology, 14:
263-283.

Cochrane, M.A.; Schulze, M.D. 1999. Fire as a recurrent event in tropical forests of the Eastern Amazon: effects on forest structure, biomass, and species composition. Biotropica, 31(1):2-16.

Cochrane, M.A.; Alencar, A.; Schulze, M.D.; Souza, C.M.; Nepstad, D.C.; Lefebvre, P; Davidson, E.A. 1999. Positive feedbacks in the fire dynamic of closed canopy tropical forests. Science, 284: 1832-1835.

DEFARA/INMET. 1999. Mapa das precipitações ocorridas em Boa Vista/RR no periodo de 01.01.97 a 25.03.99. Delegacia Federal de Agricultura em Roraima\Instituto Nacional de Meteorologia (10 Distrito de Meteorologia). 3p.

Eastman, J.R. 1995. Idrisi for Windows (v 1.0). Clark University, Worcester, Massachusetts.

Fearnside, P.M. 1992. Forest biomass in Brazilian Amazônia: Comments on the estimate by Brown and Lugo. Interciencia, 17(1): 19-27.

Fearnside, P.M. 1996. Amazonia and the global warming: Annual balance of greenhouse gas emissions from land-use change in Brazil's Amazon region. In: Levine, J.S. (ed.), Biomass Burning and Global Change, vol. 2. Massachusetts Institute of Technology, Boston, EUA. p. 606-617.

Fearnside, P.M. 1997a. Greenhouse gases from deforestation in Brazilian Amazonia: net commited emissions. Climatic Change, 35(3): 321-360.

Fearnside, P.M. 1997b. Roraima e o aquecimento global: balanço anual das emissões de gases do efeito estufa provenientes da mudança de uso da terra. In: Barbosa, R.I.; Ferreira, E.; Castellón, E. (eds.). Homem, Ambiente e Ecologia no Estado de Roraima. INPA, Manaus. p. 337-359.

Fearnside, P.M.; Graça, P.M.L.A.; Filho, N.L.; Rodrigues, F.J.A.; Robinson, J.M. 1999. Tropical forest burning in Brazilian 
Amazonia: measurement of biomass loading, burning efficiency and charcoal formation at Altamira, Pará. Forest Ecology and Management, 123: 65-79.

Fearnside, P.M.; Barbosa, R.I.; Graça, P.M.L.A. (sd). Burning of secondary forest in Amazonia: Biomass, burning efficiency and charcoal formation during land preparation for agriculture in Roraima, Brazil. (manuscrito em preparação).

Higuchi, N.; Santos, J.; Ribeiro, R.J.; Minette, L.; Biot, Y. 1997. Biomassa da parte aérea davegetação da floresta tropical úmida de terra-firme da Amazônia Brasileira. In: Biomassa e Nutrientes Florestais - Projeto BIONTE/Relatório Final. MCT-INPA/DFID, pp. 49-64.

Higuchi, N.; Santos, J.; Ribeiro, R.J.; Minette, L.; Biot, Y. 1998. Biomassa da parte aérea da vegetação da floresta tropical úmida de terra-firme da Amazônia Brasileira. Acta Amazonica, 28(2): 153-166.

Holdsworth, A. R., ; Uhl, C.. 1997. Fire in eastern Amazonian logged rain forest and the potential for fire reduction. Ecological Applications 7(2): 713-725.

Hurst, D.F; Griffith, D.W.T.; Cook, G.D. 1996. Trace-gas emissions from biomass burning in Australia. In: J.S. Levine (ed), Biomass burning and global change, Volume 2. Boston, Massachusetts Institute of Technology, p. 787-792.

IBAMA 1998. Avaliação rápida dos impactos ambientais dos incêndios sobre as florestas no estado de Roraima. Instituto Brasileiro do Meio Ambiente e dos Recursos Naturais Renováveis (IBAMA), versão revisada de setembro de 1998. 91p. (manuscrito)

IBGE 1985. Censo Agropecuário 1985 Roraima. IBGE, Rio de Janeiro.238p

IBGE 1992. Manual Técnico da Vegetação Brasileira - Manuais Técnicos em Geociencias no 1. Fundação Instituto Brasileiro de Geografia e Estatística, Rio de Janeiro. 92p.

IBGE 1995-96. Censo Agropecuário 1995-96
(Acre, Roraima e Amapá). IBGE, Rio de Janeiro. 452p.

IBGE 1999. Estimativa da população de Roraima em 1997 e 1998. Instituto Brasileiro de Geografia e Estatística / Superintendência Regional de Roraima. 1p. (manuscrito)

INPE 1998. Estimativa da área de cobertura florestal afetada pelo incêndio em Roraima, utilizando dados de multisensores. Instituto Nacional de Pesquisas Espaciais (INPE)/Divisão de Sensoriamento Remoto (outubro de 1998). 71 p. (manuscrito)

INPE 1999a. Estimativa da área de cobertura florestal afetada pelo incêndio em Roraima a partir de dados de satélite. Instituto Nacional de Pesquisas Espaciais (INPE); janeiro de 1999. 8p. (manuscrito).

INPE 1999b. Monitoramento da Floresta Amazônica Brasileira por Satélite 19971998. Instituto Nacional de Pesquisas Espaciais (INPE), fevereiro de 1999. 22p.

IPCC/OECD 1994. Greenhouse gas inventory reporting instructions (final draft). IPCC Draft Guidlines for National Greenhouse Gas Inventories (vol. 1). IPCC/OECD Joint Programme. pp. 4.69-4.72 (Total Carbon Released from Savanna Burning).

IPCC/OECD 1997. Greenhouse gas inventory: reference manual. In: Houghton, J.T.; Meira Filho,L.G.; Lim,B.; Tréanton,K.; Mamaty,I.; Bonduki,Y.; Griggs,D.J. \& Callander,B.A. (eds.) Revised 1996 IPCC Guidelines for National Greenhouse Gas Inventories (Vol. 3). pp. 5.30-5.34.

Kauffman, J.B. 1991. Survival by sprouting following fire in tropical forests of the Eastern Amazon. Biotropica 23(3): 219-224.

Kauffman, J.B.; Uh1, C.; Cummings, D.L. 1988. Fire in Venezuelan Amazon 1: Fuel biomass and fire chemestry in the evergreen rainforest of Venezuela. Oikos, 53: 167-175.

Klinge, H. ; Herrera, R. 1983. Phytomass structure of natural plant communities on spodosols in southern Venezuela: the Tall 
Amazon Caatinga forest. Vegetatio, 53: 65-84.

Luz, F.J.F. 1999. Resumo dos diagnósticos dos Assentamentos do INCRA em Roraima (1998/99). (manuscrito).

MAA/INMET 1998. Observações meteorológicas do ano de 1998, Estação de Boa Vista/RR. Ministério da Agricultura e do Abastecimento / Instituto Nacional de Meteorologia $/ 1^{\circ}$ Distrito de Meteorologia (Manaus).

Nascimento, M.T. 1994. A monodominant rain forest on Maracá Island, Roraima, Brazil: Forest structure and dynamics. PhD Thesis. Stirling (Reino Unido), University of Stirling. 146p.

Negreiros, G.H.; Sandberg, D.; Alvarado, E.; Hinckley, T.; Nepstad, D.C.; Pereira, M. 1996. Fire along the transition between the Amazon forest and Cerrado ecosystems. In: 13th Conference on Fire and Forest Metereology (27-31 october), Lorne, Australia.

Nelson, B.W.; Irmão, M.N. 1998. Fire penetration in standing Amazon forests. In: IX Simpósio Brasileiro de Sensoriamento Remoto, Santos (11 a 18 de setembro de 1998).

Nepstad, D.C.; Moreira, A.G.; Alencar, A.A. 1999a. Flames in the rain forest: origins, impacts and alternatives to Amazonian fire. Pilot Program to Conserve the Brazilian Rain Forest/World Bank. Brasilia. 16lp.

Nepstad, D.C.; Veríssimo, A.; Alencar, A.; Nobre, C.; Lima, E.; Lefebvre, P.; Schlesinger, P.; Potter, C.; Moutinho, P.; Mendoza, E.; Cochrane, M.; Brooks, V. 1999b. Large-scale impoverishment of Amazonian forests by logging and fire, Nature 398: 505-508.

RADAMBRASIL 1975-1978. Projeto RADAMBRASIL - Levantamento dos Recursos Naturais; Volumes 8, 9, 10, 11, 14 e 18. Rio de Janeiro, Ministério das Minas e Energia.

Santos, J.R.; Pardi Lacruz, M.S.; Araújo, L.S.; Xaud, H.A.M. 1998. El proceso de queima de biomassa de bosque tropical y de sabanas en la Amazonia Brasilera: experiencias de monitoreo com dados ópticos y de microondas. Revista Série Geográfica, 7: 97-108.

Schimel, D.; Alves, D.; Enting, 1.; Heimann, M,; Joos, F.; Raynaud, D.; Wigley, T.; Prather, M.; Derwent, R.; Ehhalt, D.; Fraser, P.; Sanhueza, E.; Zhou, X.; Jonas, P.; Charlson, R.; Rodhe, H.; Sadasivan, S.; Shine, K.P.; Fouquart, Y.; Ramaswany, V.; Solomon, S.; Srinivasan, J.; Albritton, D.; Derwent, R.; Isaksen, I.; Lal, M.; Wuebbles, D. 1995. Radiative forcing of climate change. In: Houghton, J.T.; Meira Filho, L.G.; Callander, B.A.; Harris, N.; Kattenberg, A.; Maskell, K. (eds). Climate Change 1995: The Science of Climate Change, Cambridge University Press, Cambridge, p, 65-131.

Scott, D.A.; Proctor, J.; Thompson, J. 1992. Ecological studies on lowland evergreen rain forest on Maracá Island, Roraima, Brazil. II. Litter an nutrient cycling. Journal of Ecology, 80: 705-717.

SENAGRO/ITERAIMA 1996. Mosaico de Imagens LANDSAT TM (1:1,000.000) do Estado de Roraima. SENAGRO, Curitiba.

Shulze, M.D. 1998. Forest fires in the Brazilian Amazon. Conservation Biology, 12(5): 948-950.

Silva, E.L.S. 1997. A vegetação de Roraima. In: Barbosa, R.1.; Ferreira, E.; Castellón, E. (eds.). Homem, Ambiente e Ecologia no Estado de Roraima. INPA, Manaus. p. $401-415$

SUDAM/IBGE 1989. Mapa de Vegetação da Amazônia $(1: 2.500 .000)$. Superintendência de Desenvolvimento da Amazônia / Instituto Brasileiro de Geografia e Estatística. Belém.

Thompson, J.; Proctor, J.; Viana, V.; Milliken, W.; Ratter, J.A. ; Scott, D.A. 1992. Ecological studies on a lowland evergreen rain forest on Maracá Island, Roraima, Brazil. I. Physical environmental, forest structure and leaf chemestry. Journal of Ecology, 80: 689-703. 
Uhl, C.; Kauffman, J.B.; Cummings, D.L. 1988. Fire in the Venezuelan Amazon 2: Environmental conditions necessary for forest fires in the evergreen rainforest of Venezuela. Oikos, 53: 176-184.

Villela, D.M. 1995. Nutrient cycling in a monodominant and other rain forest types on Maracálsland, Brazil. PhD Thesis. Stirling (Reino Unido), University of Stirling. $138 \mathrm{p}$. 